\title{
Power Electronic Circuits and Control Strategies for Improving the Performance of EVs \& HEVs
}

\author{
Dr. G. Sree Lakshmi ${ }^{1}$ and G. Divya ${ }^{2}$ \\ ${ }^{1}$ Professor, CVR College of Engineering/ EEE Department, Hyderabad, India \\ Email: sreelakshmisampath@gmail.com \\ ${ }^{2}$ Asst. Professor, CVR College of Engineering/ EEE Department, Hyderabad, India \\ Email: divya.gongidi@gmail.com
}

\begin{abstract}
To give cleaner air to future generation with less pollution and to protect our atmosphere from depletion of ozone layer there is a great need of adaptation of emission free vehicles like EVs and HEVs. Even though Government is giving many incentives and subsidies in making the shift towards EVs and HEVs, but due to lack of storage system, less improvement in power electronics and drive system, there is no prominent increase in the emission free transportation on road. With good storage system the cost of the EVs and HEVs are increasing when compared to ICE vehicles. A huge research is taking place in this area. This paper gives the details of Converters, Inverters and Control strategies used in EVs and HEVs to compare which is best suitable to increase the performance of EVs and HEVs. Basic Conventional Vehicle and Hybrid Vehicle system simulation results are taken, and they are compared to understand the advantages and improving the usage of EVs and HEVs with proper storage system.
\end{abstract}

Index terms: Electric Vehicle (EV), Hybrid Electric Vehicle (HEV), Internal Combustion Engine (ICE).

\section{INTRODUCTION}

In order to increase the HEVs performance the power electronic circuit is playing a prominent role. The main important Power electronic circuits in HEVs are Converters and Inverters. Converter is used to increase the voltage levels in EVs whereas the inverter is used to convert AC to DC. In addition to above uses there are many other advantages by using Inverters and Converters. In order to apply the concept for the HEVs it is very important to know which converters and inverters can be used in Electric Vehicles. So, this paper demonstrates the classification of the both converters and inverters used in HEVs. In order to understand the characteristics of Conventional and Hybrid vehicle it is essential to understand all the Inverters and Converters topologies used in to decide which is best. Previous simulation analysis and results have been taken and analyzed. The results show that EVs and HEVs have good advantages than that of Conventional Vehicles. The performance can be further increased by using proper combination of Inverters and Converters topology.

\section{CONVERTERS}

DC-DC converters are the main converters which are used in HEVs. Converters help to interface connection between battery and any energy storage device to DC-link. As there is need for decrease or increase of voltage level, at least one DC$\mathrm{DC}$ converter is needed. So a high powered DC/DC converter is needed for supplying power for the Electric Vehicles. Power converter range varies from $20 \mathrm{~kW}$ to $200 \mathrm{~kW}$. There are three different types of DC-DC converters. Mostly Bi-directional DC-DC converters are needed as power is made to flow in both the directions [1].

A. Isolated Converters

\section{Traditional DC-DC Converters:}

a) Boost Converter: This type of converter uses only positive voltage gain which is greater than that is needed for motor action. So, Boost converter is mostly used in EVs. The polarities are same for input and output.

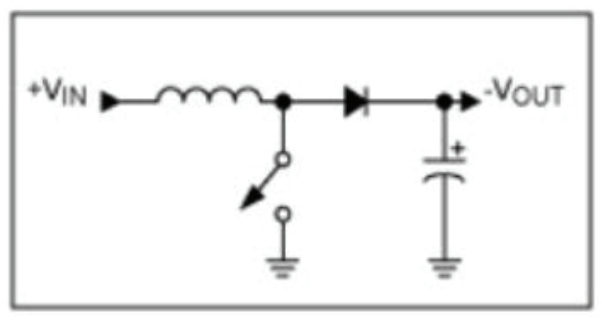

Figure 1. Boost Converter

b) Buck-Boost: It is used for increasing and decreasing the voltage level.

c) Cuk: It is current-Voltage- Current Converter. It is used for increasing and decreasing the voltage level. Mostly used for storing energy.

d) Charge Pump Converter: It is used in low power application and can lower voltage level as well as inversing the level of voltage.

\section{Interleaved $D C-D C$ Converter:}

The main advantage of this type of converter is it can increase voltage level more than four percent. The current ripple at input side and voltage ripples at output side will be 
minimum in IDC. This concept of minimizing the ripples makes it as profitable Converter topology.

\section{Multi-Port:}

These devices help in transferring energy by taking from multi inputs and delivering to single output.

\section{Isolated Converter:}

This type of converter is used where there is need of Isolation from input to output. It also has high ratio in increasing and decreasing voltage level. Primary stages which are involved in this type of converters are DC to AC to DC. $\mathrm{AC}$ which is converted in between and is increased to high voltage levels by using a high frequency transformer which provides high voltage gains. This type of converters is used in low to medium applications. There are four subdivisions made in these converters.

\section{a) B-Converters:}

Half-Bridge: It consists of two same half bridge converters with outputs connected in anti-parallel

Full-Bridge: This is mostly used in isolated converters as it reduces voltage and current pressures on power electronic devices like diodes and switches. It also improves overall device efficiency and reduces cost.

\section{b) ZC-Source:}

It has only one stage that is DC to AC. Advantages of smooth starting, reducing voltage stress on gates and reducing current ripples. Drawback of this topology is it has limited boosting capability because of limited voltage gain.

c) SAHVC:

Sinusoidal Amplitude High Voltage Bus Converter is Low di/dt and $d v / d t$ values both in ON and OFF modes of switches helps in reducing switching losses and maintain high power density.

d) $M P C$ :

Multi port Converter is best topology for EVs as it has many advantages of decreasing size of components, efficiency increases, reduces ripples of input current and output voltage and has handling high power.

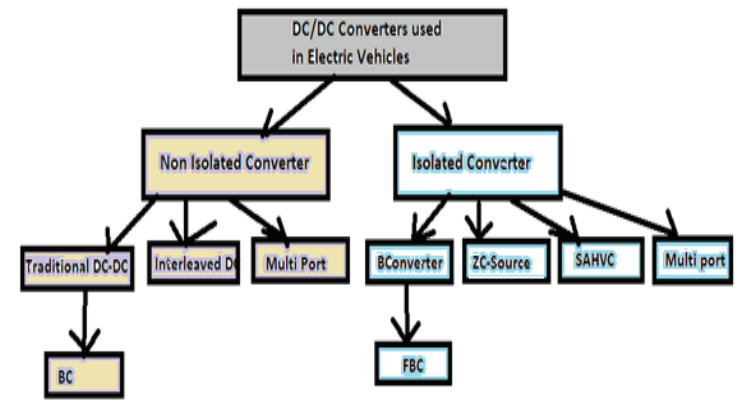

Figure 2. Block diagram of different converters used in EVs and HEVs

\section{WORKING OF DC-DC CONVERTERS USED IN EVS}

\section{A. B-Converter:}

By decreasing input current level, the input voltage level can be increased with this converter. Boost converter is one type of switch mode power supply. So, it also has one energy storing element, inductor in series with the source of DC. This combination helps to reduce the current ripples at input side. Whereas output voltage ripples are reduced by connecting capacitor filter. The advantage of using this converter is input current will be continuous and operation is simple, and cost is less. Voltage gain at output is less than four percent. All the working and advantages make Boost converter applicable for EVs [2].

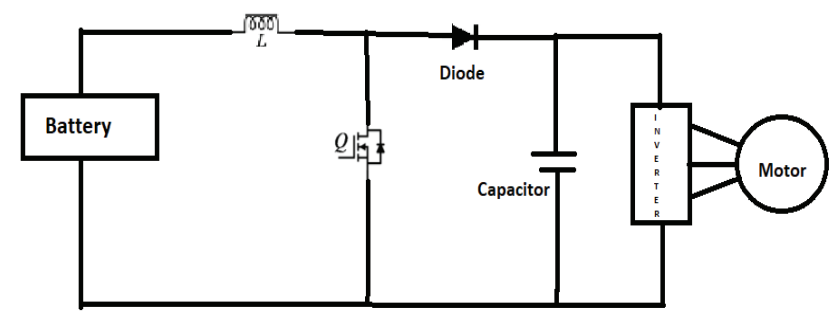

Figure 3. B-Converter topology

\section{B. Interleaved four phase Boost Converter:}

This allows reducing ripples in input current and output voltage as current ripples are higher than switching frequency. This topology consists of 4 inductors. Switching period and total number of phases will decide phase shifting of power switching devices. The current delivered by the source is shared equally by step up converters. With this advantage there is reduction in size of capacitor and inductor. This is the reason for choosing this converter for EVs.

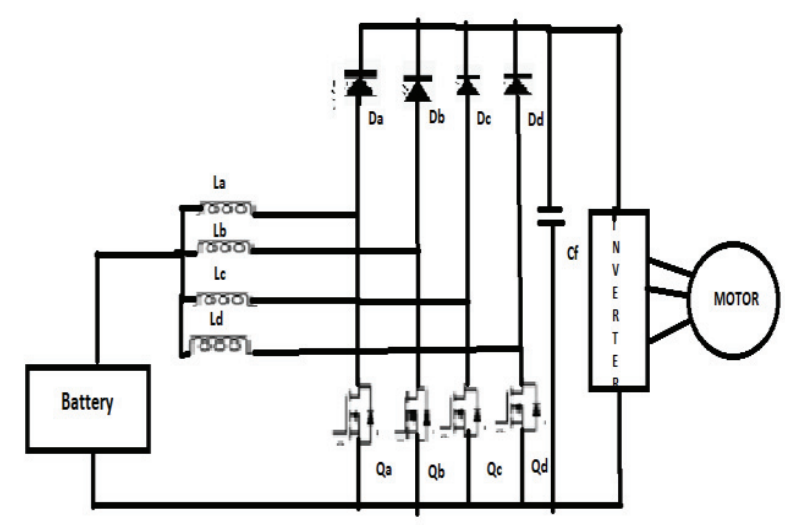

Figure 4. Interleaved four phase Boost Converter topology

\section{Full-Bridge Boost Converter:}

This topology consists of three steps inverter operation, stepping up the voltage and again rectification operation. Output voltage is made constant even if input voltage is varying by properly handling the PWM duty cycle. The negative side of hysteresis loop is used which results in reduction in core saturation. The efficiency of converter is 91 percent when $30 \mathrm{~kW}$ load is applied. 


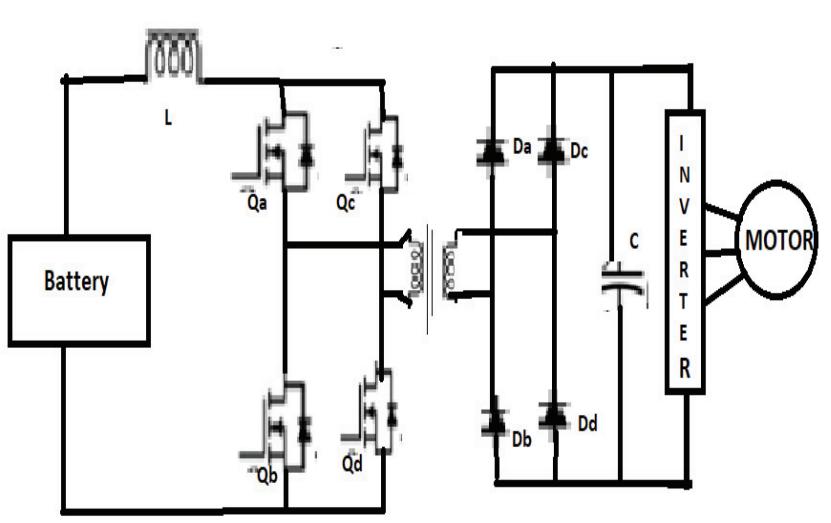

Figure 5. Full-Bridge Boost Converter circuit

\section{ZC-Source:}

By this Converter the efficiency can be increased more than Full-Bridge Boost Converter, easy to control, light weight and small. With the help of Zero Voltage Switching Converter soft switching and cold starting is possible. The model is like dual half bridge circuitry which is placed on both the sides of transformer. Bi-directional power flow is possible without adding additional devices. Splitting DC Capacitor is needed in order to handle full load current, because stress due to high voltage across power switches in high power applications. ZCSource also needs large filters to reduce ripples in output voltage.

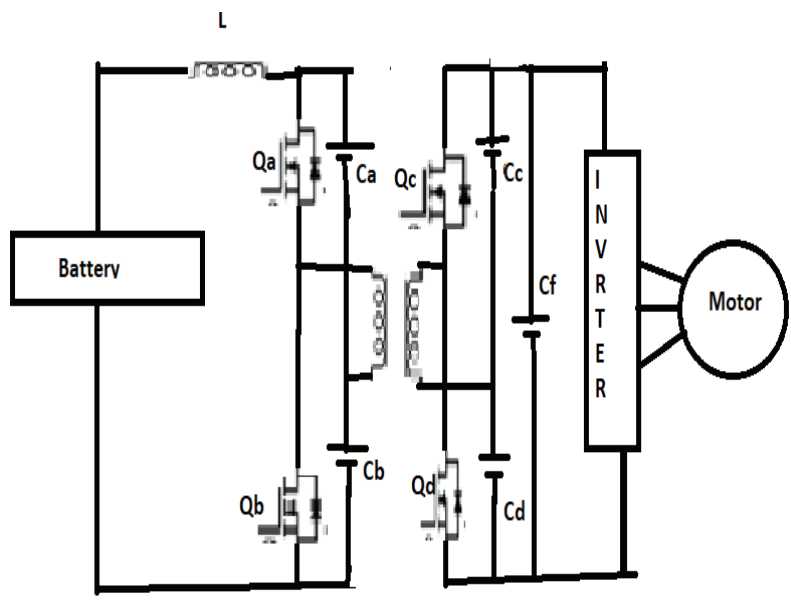

Figure 6. ZC-Source

\section{INVERTERS USED IN HYBRID VEHICLES}

EVs operate with high DC bus voltage and high value of power capacity around $48 \mathrm{~V}$ to $800 \mathrm{~V}$ with $10 \mathrm{~kW}$ to $200 \mathrm{~kW}$ power capacity. Inverter will change the speed of the motor by rotating frequency. It also controls motor in EVs and determines driving behavior. In addition to above function inverter will capture the energy during regenerative braking as well. So, efficiency of vehicle is determined by the inverter performance [3].

\section{A. Traction Inverter types:}

1. Packaged box-type inverter: It has 6-pack which is filled with six pack gel.

2. Integrated inverter design: Small and fully encapsulated power modules which are placed in compartment of drive train. Electric machines can be integrated into as fully transmission part by integrating power inverter in same circuit. This type of inverter design importance is growing because of very attractive features like cooling, vibration, size and cost.

3. Multi-level Inverter: The structure of this inverter helps the vehicle in achieving high voltages to meet the needs of heavy vehicles. As levels increases the output obtained will have number of steps and harmonic wave distortion in the output also decreases.

4. Cascaded H-Bridge inverter: This construction consists of series of full bridge inverter units in three phases. This unit serves as battery. In this each low voltage battery is isolated through switches and leakage current is less when switch is in on condition [4]-[6].

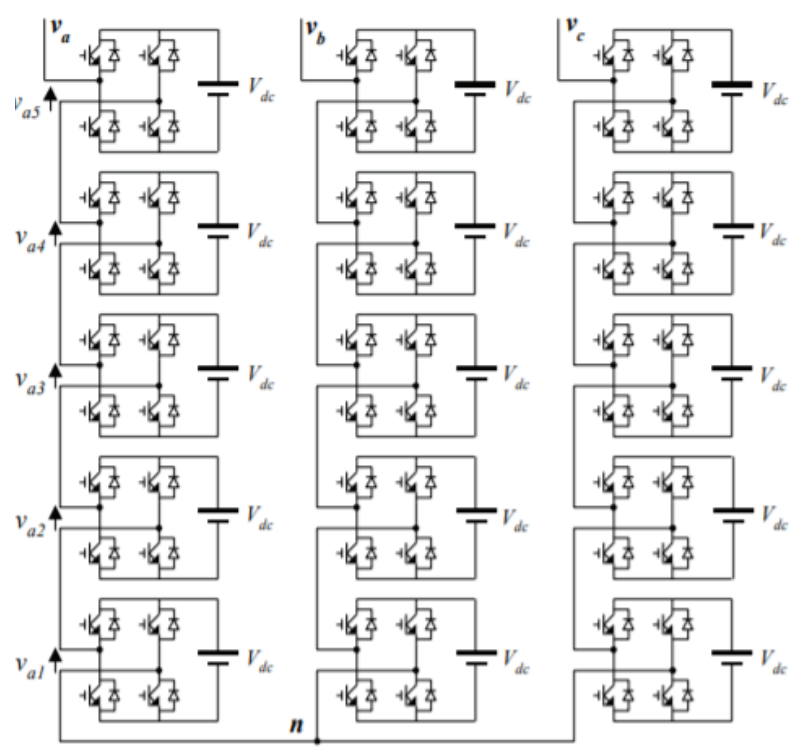

Figure 7. Cascaded H-Bridge inverter circuitry

\section{Control Strategies USEd IN EVS}

Generally, the Hybrid Electric Vehicle requires controlling the drive train. Main aim of any control strategy is to reduce error. Specially in case of meeting the power demand, improving efficiency, State of Charge of battery and storing energy even while applying the brakes. Normally PWM Control is used for DC Motors and Induction Motors use Field Oriented Control (FOC) and Direct Torque Control (DTC). 
These control strategies are controlled by many different algorithms which are introduced in recent studies. Those control strategies are Classical Control Proportional Integral Derivative (PID), adaptive control, Fuzzy control, Neuro Network control.

\section{A) PID Control:}

Generally, Inputs for the controller are torque and speed of the road. The voltage and current are drawn depending on requirement. Here the voltage demanded is compared to voltage which is given as reference. The difference which is obtained by comparing these two is given as error signal to PID controller. Depending on the error signal the voltage is decreased, and the current value is increased depending on the requirement by the HEVs. In HEVs there is problem with electric phase with respect to rising time and settling time. This control strategy will help in managing to which not possible with normal control strategies [8].



Figure 8. PID Control Circuitry

\section{B) Fuzzy Control:}

In the Fuzzy control only the PID is substituted with the Fuzzy block and an Integrator and the result obtained after comparison of reference and output is used to decide how much voltage is needed and depending on that voltage level is managed to meet the power demand [7].

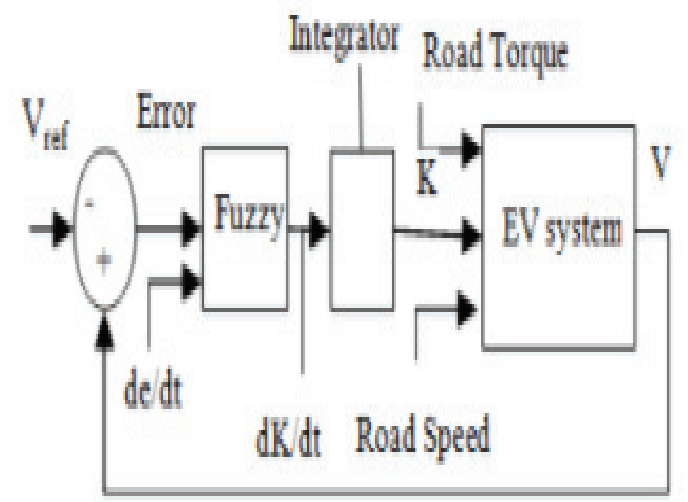

Figure 9. Fuzzy Control Circuitry

\section{C) Neural Network Control:}

The inputs needed for this model are torque, SOC of battery and speed. There are four different layers in this control they are input layer (m), output layer (n), hidden layer and undertaken layer. Selection of parameters Neural Network Control Strategies is determined by equation :

$k=\sqrt{m+n+\beta}$

$\beta$ is the constant value which is approximately equal to from value 1 to 10 . This method is trained by Levenberg-Marquardt algorithm. This method is trained by human brain. With proper training Neural method can produced maximum torque and reduce fuel consumption as well when compared to other methods. Fig 10 shows the neural network model and Fig. 11. shows the structure of neural network [9].

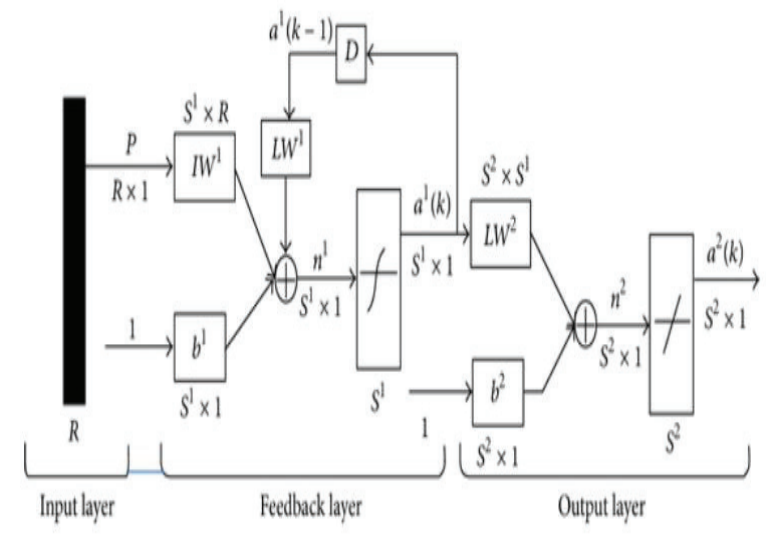

Figure 10. Neural Network Model

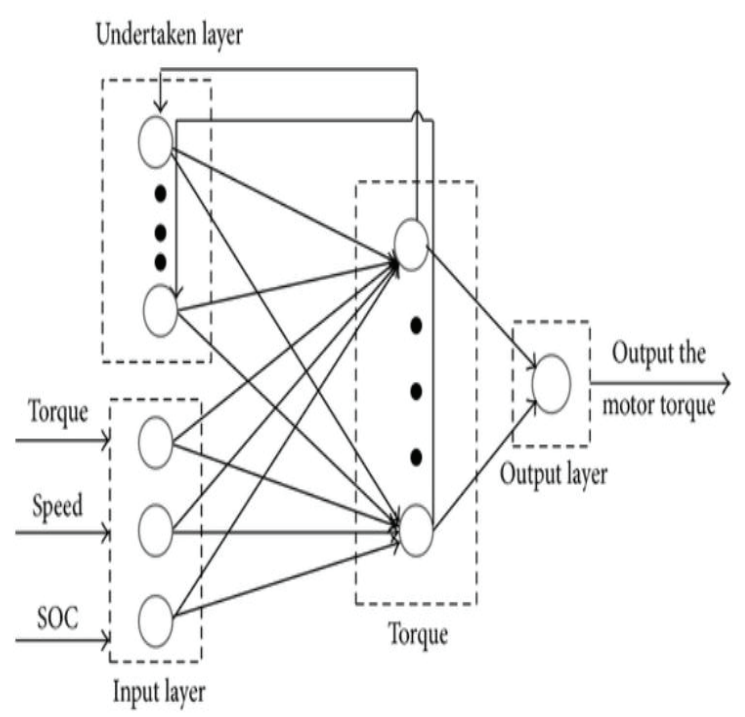

Figure 11. Structure of Neural Network 


\section{Simulation Results of Hybrid Electric VEHICLE}

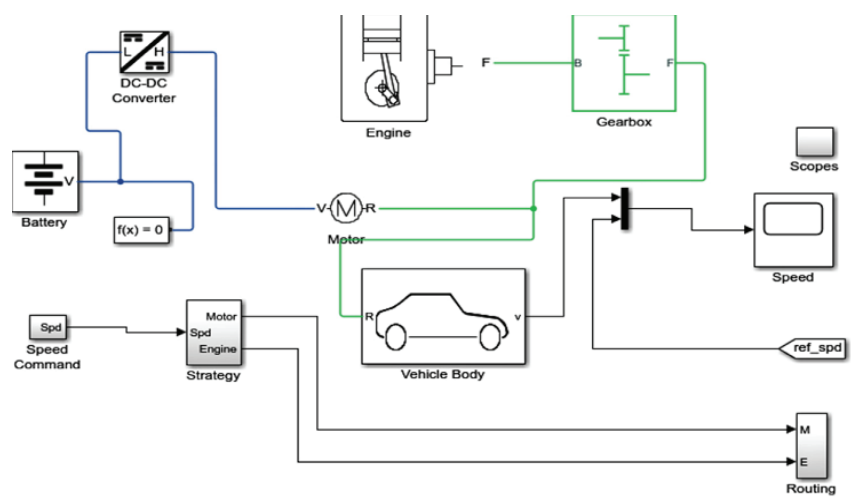

Figure 12. Block diagram of Basic Hybrid Electric Vehicle

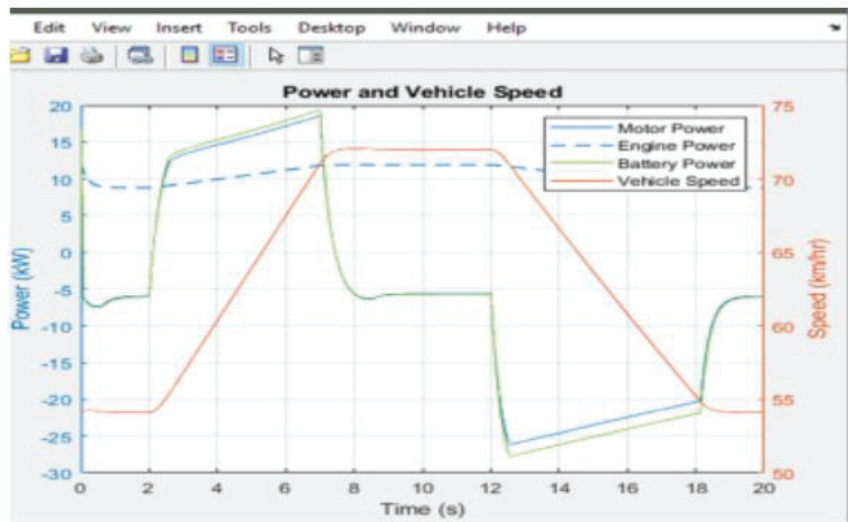

Figure 13. Simulation results of Hybrid Electric Vehicle of Power vs Vehicle Speed

VII.Simulation Results of Conventional Vehicle WITH CITY DRIVE CYCLE
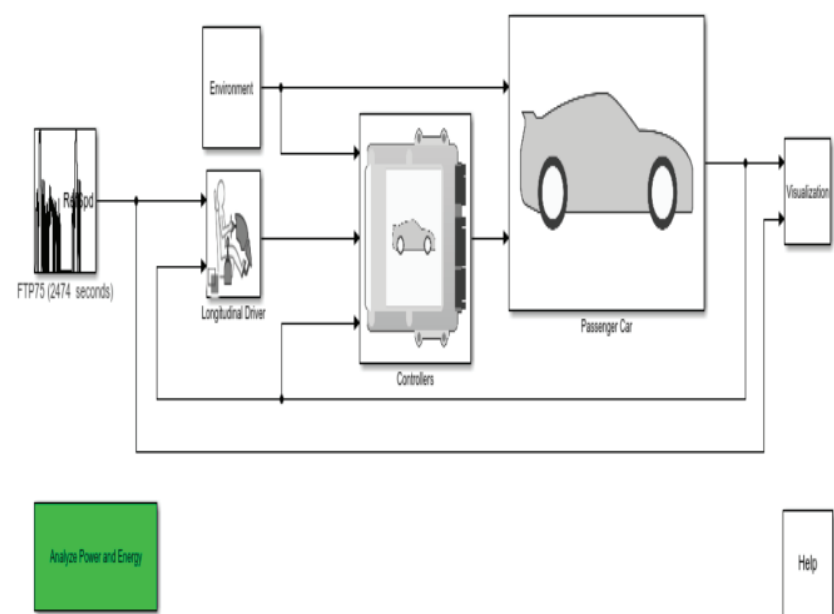

Figure 14. Block diagram of basic Conventional Vehicle with driving cycle
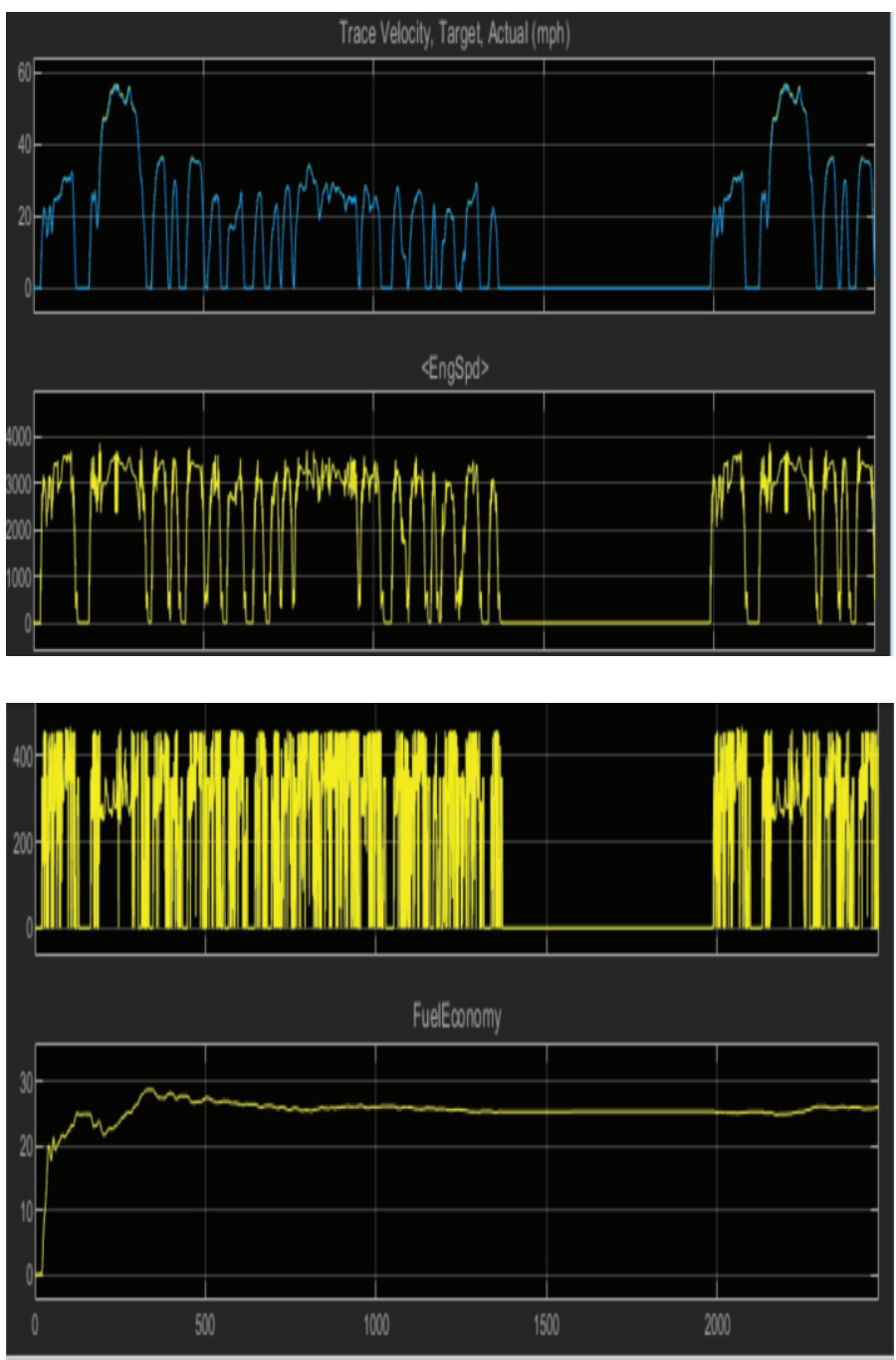

Figure 15. Simulation result of Conventional vehicle of Speed, fuel economy [5]

In the Fig. 12 block diagram of Basic Hybrid Electric Vehicle is shown and in Fig. 13 the power verses vehicle speed characteristics is shown for HEV. In Fig.14 Block diagram of basic conventional vehicle with driving cycle is shown. In Fig. 15 simulation results of conventional vehicle of speed fuel economy is shown. From the above two simulations from Fig.13 and Fig.15 which have been taken from two different analysis, it is understood that EVs have a very good Speed Velocity, Battery state of charge and Engine power when compared to Conventional vehicles. In addition to these added features EVs are environmentally friendly. With minimum development in EVs technology the simulation results have shown greater results. So, it is necessary to improve Converter and Inverter part along with other power electronic circuit in order to receive customer acceptance in a large number. Especially in the case of fuel storage and usage of stored fuel where circuits which involve electronic circuit comes into existence. 


\section{CONCLUSIONS}

The paper has projected on importance of power electronic circuits and control strategies for EVs and HEVs. The basic Inverters, Converters and control strategies introduction are given. Also, simulation results which have been taken show that the HEVs give best results when compared to conventional ICE vehicles. This show if major improvements can be made in drive system and power electronic circuit increases the performance of EVs and HEVs. With increase in performance of emission less electric vehicle more adoption by customers can be gained.

\section{REFERENCES}

[1] Monzer Al Sakka, Joeri Van Mierlo, and Hamid Gualous, "DC/DC Converters for Electric Vehicles" in In. book: "Electric Vehicles- Modelling and simulation," Sep-2011, J. Clerk Maxwell, a Treatise on Electricity and Magnetism, $3^{\text {rd }}$ ed., vol.2. Oxford: Clarendon, 1892, pp.68-73.

[2] Sajib Chakraborty 1,2, Hai-Nam Vu 1,2, Mohammed Mahedi Hasan 1,2, Dai-Duong Tran 1,2, Mohamed El Baghdadi 1,2 and Omar Hegazy 1,2,*," DC-DC Converter Topologies for Electric Vehicles, Plug-in Hybrid Electric Vehicles and Fast Charging Stations: State of the Art and Future Trends", 25 April 2019.K. Elissa.

[3] Leon M. Tolbert, Fang Z. Peng, Thosmas G. Habetler, "Multilevel inverters for Electric Vehicles Application," WPET98, Dearborn, Michigan, October 22-23, 1998. Pp-79-84.

[4] Abrar Ahmed,Palasksh Yelamali,R.UdayaKumar,"Modelling and simulation of hybrid technology in vehicles", The 6th
International Conference on Power and Energy Systems Engineering (CPESE 2019), September 20-23, 2019, Okinawa, Japan",volume 6 February 2020, Pages 589-594M.

[5] Conventional Vehicle Spark-Ignition Engine Fuel Economy and Emissions",

https://in.mathworks.com/help/autoblks/ug/conventionalvehicle-fuel-economy.html".

[6] Syed Mohd Harussani Syed Omar, N. M. Arshad, I. M. Yassin, Mohd Hadi Anuar Mohd Fakharuzi, Tom Ward, “ Design and Optimization of a Powertrain systems for a prototype fuel cell electric vehicle," Pages: 1401-1413, Journal of Mechanical Engineering and Sciences, Vol 8,Published 30 june 2015.

[7] S.k.jha, Anil Kumar Yadav,Prerna Gaur," Power management for electric vehicle with PID and Fuzzy logic controllers", 2017 International conference of Electronics, Communication and Aerospace Technology (ICECA)," April 2017 DOI: 10.1109/ICECA.2017.8212731.

[8] Hmidi Mohamed Elhedi, Ines Ben Salem,Lilia El Amaroui,"2DOF PID for dynamic control of drive system hybrid vehicle electrical".

[9] "Ruijun Liu, ${ }^{1}$ Dapai Shi, ${ }^{1}$ and Chao $\mathrm{Ma}^{1}$ ", Real-Time Control Strategy of Elman Neural Network for the Parallel Hybrid Electric Vehicle", Volume 2014 |Article ID 596326 | https://doi.org/10.1155/2014/596326. 